Vikramaditya Singh Rathore, Jahnavi Kantamneni, Ajinkya Jamadar, Subham Anupam, Devanshi Kachchap

\title{
Manifestations of traditional knowledge in water systems: The cases of the Kuchaman Fort and Rathi Haveli, Rajasthan
}

\author{
Manifestaciones de conocimientos tradicionales en \\ sistemas hídricos: Los casos del Fuerte y la Rathi \\ Haveli de Kuchaman, Rajastán
}

\author{
Manifestações do conhecimento tradicional em \\ sistemas hídricos: Os casos do Forte e Rathi Haveli de \\ Kuchaman, Rajasthan
}

\author{
Keywords $\mid$ Palabras clave $\mid$ Pallaviras chave \\ Resilience, Sustainability, Rajput architecture, Rainwater, Water tanks \\ Adaptabilidad, Sostenibilidad, Arquitectura rajput, Agua de lluvia, Depósitos de agua \\ Resiliência, Sustentabilidade, Arquitectura Rajput, Água da chuva, Tanques de água
}

\begin{abstract}
Resumen | Resumo
Water scarcity in the arid region of Rajasthan incentivized a sophisticated indigenous knowledge of water systems. This traditional knowledge, which was rooted in this geographical context, supported the prosperity of this region for centuries. The systemic degradation of this knowledge has increased the demand for external resources, leading to a constant need for expanding infrastructure. It is therefore time to look back to this traditional wisdom in search of sustainable alternatives. This study focuses on traditional water conservation systems in the purview of the spatial planning and the architectural elements in the Fort and the Rathi Haveli of Kuchaman, Rajasthan. These two traditional complexes have been studied for the interest and similarities found in the way they manage their water resources. This study highlights the timeless simplicity of the identified indigenous strategies and envisions possible manifestations of this knowledge for contemporary practice.
\end{abstract}

La escasez de agua en la árida región de Rajastán incentivó el sofisticado conocimiento local sobre sistemas hídricos. Estos conocimientos tradicionales, arraigados en su contexto geográfico, fueron la base de la prosperidad de la zona durante siglos. El deterioro sistémico de estos conocimientos ha incrementado la demanda de recursos externos, con la necesidad constante de ampliar las infraestructuras. Es pues el momento de volver a los conocimientos tradicionales para buscar alternativas sostenibles. Este estudio se centra en los sistemas tradicionales de conservación del agua en el ámbito de la planificación espacial y los elementos arquitectónicos del Fuerte y el Rathi Haveli de Kuchaman, Rajastán. Estos dos complejos tradicionales se han estudiado por su interés y las semejanzas encontradas en su forma de gestionar 
los recursos hídricos. Este estudio destaca la sencillez atemporal de las estrategias autóctonas identificadas e imagina posibles aplicaciones de estos conocimientos en las prácticas actuales.

A escassez de água na região árida de Rajasthan incentivou um sofisticado conhecimento local dos sistemas hídricos. Este conhecimento tradicional, que estava enraizado neste contexto geográfico, sustentou a prosperidade desta região durante séculos. A degradação sistémica deste conhecimento levou a um aumento da procura de recursos externos, levando a uma necessidade constante de expansão de infra-estruturas. É, portanto, o momento de olhar para trás para esta sabedoria tradicional em busca de alternativas sustentáveis. Este estudo foca-se nos sistemas tradicionais de conservação da água no âmbito do planeamento espacial e dos elementos arquitectónicos no Forte e no Rathi Haveli de Kuchaman, Rajasthan. Estes dois complexos tradicionais foram estudados pelo interesse e semelhanças encontradas na forma como gerem os seus recursos hídricos. Este estudo destaca a simplicidade intemporal das estratégias indígenas identificadas, e prevê possíveis manifestações deste conhecimento na prática contemporânea.

\section{Introduction}

Scorching sun, scanty rains, barren land, and water scarcity make the arid state of Rajasthan a tough place to live. The harsh climate influences many aspects of life, including the hydrology of the region. In certain areas, even the groundwater is saline, leading to traditional settlements primarily relying on sophisticated yet straightforward rainwater harvesting techniques. The ingenuity of these systems and their constant experimentation and evolution put forward this multigenerational body of knowledge. The water structures found in these settlements can be viewed as the manifestations of an ever-evolving knowledge of water conservation and management. The embodiment of this knowledge into local culture has given us the bespoke way of life that can be found in all traditional settlements of Rajasthan.

Traditional architecture as an embodiment of indigenous $\underline{\text { knowledge systems }}$

India is a very geographically diverse region. A resource as vital as water has been managed by the different settlements within the purview of this diversity. In mountainous regions of the north and northeast, water from streams was driven into a network of water channels that irrigated fields and provided water to settlements. In the south, canals drew water from the perennial rivers and channeled it into a series of tanks - from which the water was provided to the towns. Shallow groundwater levels in the central region enabled a water system that primarily relied on groundwater. Check dams, nahar and qanat systems were used to capture runoff from natural catchments and replenish these aquifers (Narain \& Agarwal, 1999). Saline groundwater and lack of surface water led to the development of a traditional water system that helped a civilization flourish in the extreme climatic conditions of Rajasthan.

The essence of traditional settlements in Rajasthan would be incomplete without the numerous man-made water bodies and structures dotted across its territory. Deprivation of conventional natural sources of water led to the development of water systems that used an array of techniques to harvest rainwater and orchestrate an artificial ecosystem. Their architecture revolves around the element of water and is attuned to aspects like source (groundwater, rainwater or runoff), taste, quality and quantity. Such a profound reverence toward water is rooted in a local culture that even has more than 44 names for clouds, based on their shape, type, movement and character (Mishra 1995). A deep understanding of the land and its water has enabled a traditional knowledge system within the community that guided its development for ages.

As opposed to the current paradigm of centralized systems of water management, people traditionally relied on decentralized systems, where each one had its own technology which allowed for heterogeneous growth. "There were different systems ranging from water harvesting and storage to distribution mechanisms. Each one of them evolved in situ and underwent organic modifications and improvements" (Jacob 2011: 6). Despite the differences, their engineering mechanisms were based on elementary principles. From initial capture to storage, structures were 
engineered for passive cooling, large spans, public access and minimal exposure, drawing purely on their geometry. The use of local materials, natural gradients, local labor and passive techniques, coupled with socio-cultural layers, yielded a traditional ethos that reflected the values of selfsufficiency and autonomy.

\section{Methodology}

This paper analyses two heritage structures from the context of Kuchaman city. As part of the study, published works on individual, communal and public water storage and distribution structures that constituted the traditional rainwater harvesting systems of Rajasthan were reviewed. Through the study of heritage structures in reference to the traditional rainwater harvesting system, the paper aims to explore the potential of reviving traditional water systems. Kuchaman Fort, which was the royal residence of the Thakur, was designed with the system that employed the finest practices and resources of that time. Unfortunately, it is currently in a state of decay. Rathi Haveli, a common man's residence within the fortified city, is one of the few structures that has a functional water system, with its components evolving over time.

The water network of the fort was studied using measured drawings, photo-documentation, and mapping. Tentative calculations of catchment harvesting capacities and channel and tank carrying capacities were undertaken based on these documents to emphasize the efficiency of the system.

Rathi Haveli has been studied for the contemporary relevance of its water system, while authors and their team documented the Kuchaman Fort and precinct as part of their submission for Louis I. Kahn Trophy of NASA India in 2017, representing their college, the School of Planning and Architecture of Bhopal.

The study outlines learnings from traditional knowledge systems and the attributes, associated value systems and spatial strategies supporting them. In conclusion, it presents a set of principles that could develop a contextspecific design of a rainwater harvesting system for larger settlements.

\section{Water systems at the different thresholds in Rajasthan}

Water structures were broadly classified into three categories: subterranean and enclosed, subterranean and open and surface level structures (Fig. 1). Efforts to reduce evaporation losses led to a majority of these water systems being subterranean enclosed structures that usually store potable water. The remaining ones are open structures, suitable for washing and watering domesticated animals. Some of these open structures are stepwells that allow for mass access and facilitate social congregations, intertwining this basic need with social life.

The water systems are not a single homogeneous mechanism, but a conglomerate of decentralized water structures. These were divided into different physical thresholds of the settlement: individual, communal, public and the royal complex (Fig. 2).

Conceptually, there are four components of a water system: harvesting, channeling, storage, and drawing and engineered for passive cooling, large spans, public access and minimal exposure, drawing purely on their geometry. The use of local materials, natural gradients, local labor and passive techniques, coupled with socio-cultural layers,

Figure 1: Typologies of water structures: (a) Subterranean covered, (b) Subterranean open, (c) Surface level
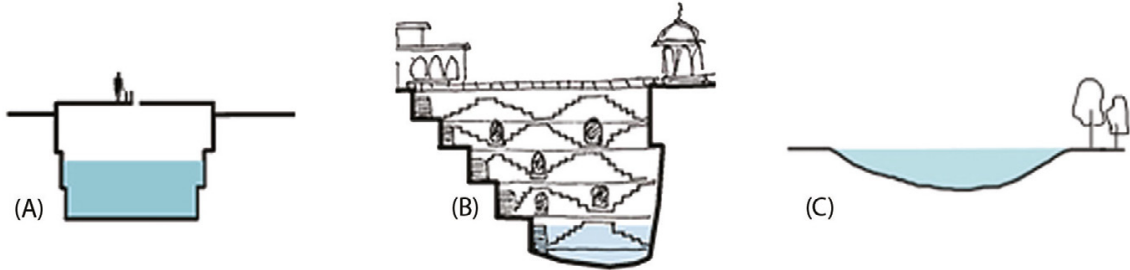

Figure 2: Water structures at physical thresholds of a settlement: (A) Individual threshold, (B) Communal threshold, (C) Public threshold

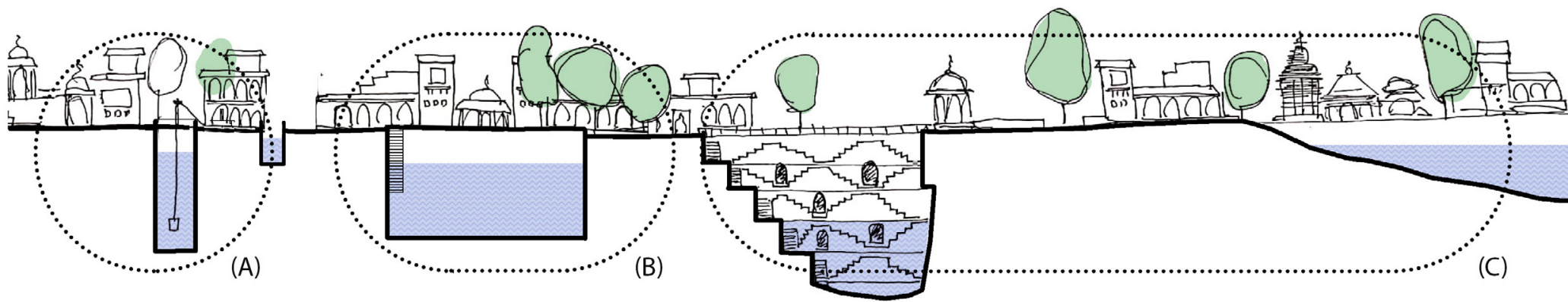


yielded a traditional ethos that reflected the values of selfsufficiency and autonomy.

\section{Methodology}

This paper analyses two heritage structures from the context of Kuchaman city. As part of the study, published works on individual, communal and public water storage and distribution structures that constituted the traditional rainwater harvesting systems of Rajasthan were reviewed. Through the study of heritage structures in reference to the traditional rainwater harvesting system, the paper aims to explore the potential of reviving traditional water systems. Kuchaman Fort, which was the royal residence of the Thakur, was designed with the system that employed the finest practices and resources of that time. Unfortunately, it is currently in a state of decay. Rathi Haveli, a common man's residence within the fortified city, is one of the few structures that has a functional water system, with its components evolving over time.

The water network of the fort was studied using measured drawings, photo-documentation, and mapping. Tentative calculations of catchment harvesting capacities and channel and tank carrying capacities were undertaken based on these documents to emphasize the efficiency of the system.

Rathi Haveli has been studied for the contemporary relevance of its water system, while authors and their team documented the Kuchaman Fort and precinct as part of their submission for Louis I. Kahn Trophy of NASA India in 2017, representing their college, the School of Planning and Architecture of Bhopal.
The study outlines learnings from traditional knowledge systems and the attributes, associated value systems and spatial strategies supporting them. In conclusion, it presents a set of principles that could develop a contextspecific design of a rainwater harvesting system for larger settlements.

\section{Water systems at the different thresholds in Rajasthan}

Water structures were broadly classified into three categories: subterranean and enclosed, subterranean and open and surface level structures (Fig. 1). Efforts to reduce evaporation losses led to a majority of these water systems being subterranean enclosed structures that usually store potable water. The remaining ones are open structures, suitable for washing and watering domesticated animals. Some of these open structures are stepwells that allow for mass access and facilitate social congregations, intertwining this basic need with social life.

The water systems are not a single homogeneous mechanism, but a conglomerate of decentralized water structures. These were divided into different physical thresholds of the settlement: individual, communal, public and the royal complex (Fig. 2).

Conceptually, there are four components of a water system: harvesting, channeling, storage, and drawing and distribution mechanisms. These components can be found in different forms in different water structures. They are agor (catchment); open drains or terracotta pipes for channeling; kui, kund or taanka etc. for storage; charkhi (pulleys) or rehat (Persian wheels) for drawing water; and

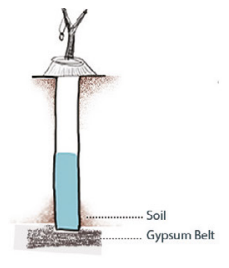

(A)

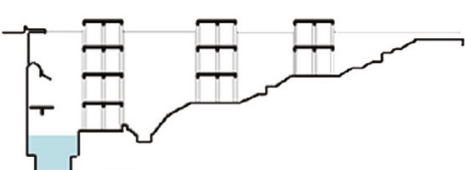

(A)

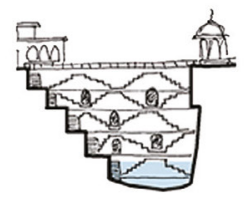

(D)

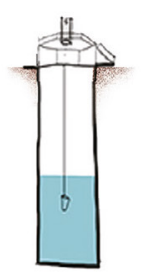

(B)

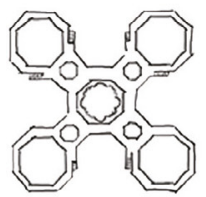

(B)

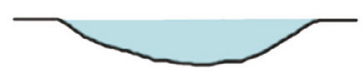

(E)
Figure 3: Types of water structures at individual threshold in Rajasthan: (A) kui, (B) small kund, (C) small taanka

(C)

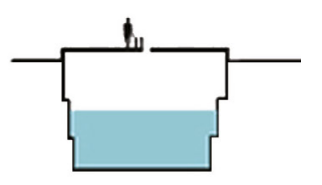

(C)

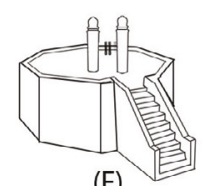

Figure 4: Types of water structures at communal and public thresholds in Rajasthan: (A) Bawdi (B) Chautina kua (C) Large taanka (D) Jhalara (E) Talaab (F) Large kund 


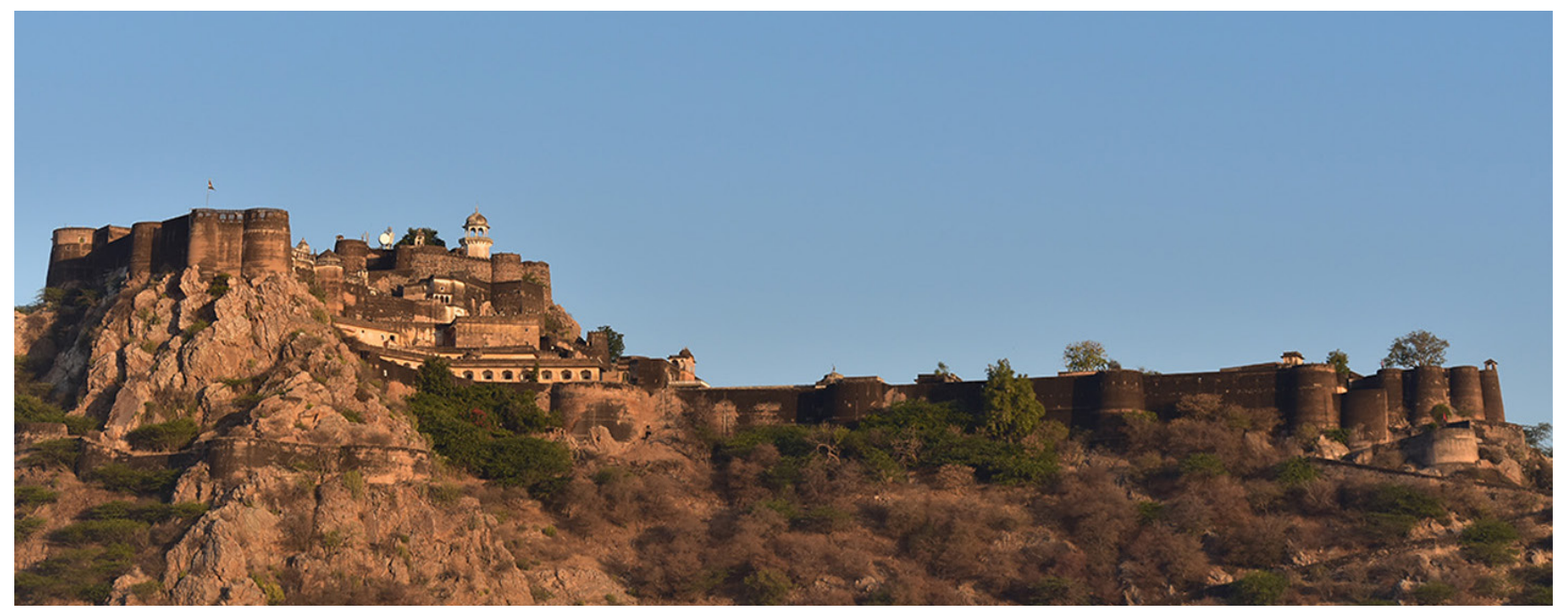

Figure 5: Kuchaman Fort

bawdi (step-wells) or talaab (lakes) for public access and distribution.

At an individual level, the Haveli or dwelling unit is equipped with a taanka (a subterranean tank) as big as a room (Fig. 3). It is used to store the rainwater received from the terrace catchment. With the given rainfall and accumulated volume, a taanka can provide water for about 8-10 months for a family of five (Jacob 2011: 104). The individual ownership of these structures instils a sense of belonging and reflects the value of self-sufficiency.

The agor or catchment is protected from impurities by treating it as a sacred entity. Measures to limit the scope of contamination of water, like the designation of pathways on catchment areas, barriers to keep animals away, and pillars etched with symbols used for mass communication were part of the local way of life (Mishra 1993).
At a communal level, larger tanks were built and maintained by the community in public spaces of the neighborhood (Fig. 4). The rich invested in the construction of such structures, in turn acquiring merit and social status. The practice of building commemorative structures in their memory guaranteed renewed patronage for the water structures, while others from the community provided labor in exchange for a stake in its use and upkeep. These structures accommodated festivities and were the center of the social life of the community. The tessellated steps of the bawdi and jhalara (two types of stepwells) are aesthetically comparable to open-air theatres. Some of the retaining walls were decorated with symbols or statues to communicate the water level.

At a public level, larger water structures in the form of ornate stepwells or bawdis were built by the rulers. With enormous capacities in comparison to communal facilities,

Figure 6: Traditional lime plaster replaced by ceramic tiles in the pool of Sunheri Burj, in the Ranvas at Kuchaman Fort: (A) Original materials used in construction ( kuchamanfort.com); (B) Poor conservation practices
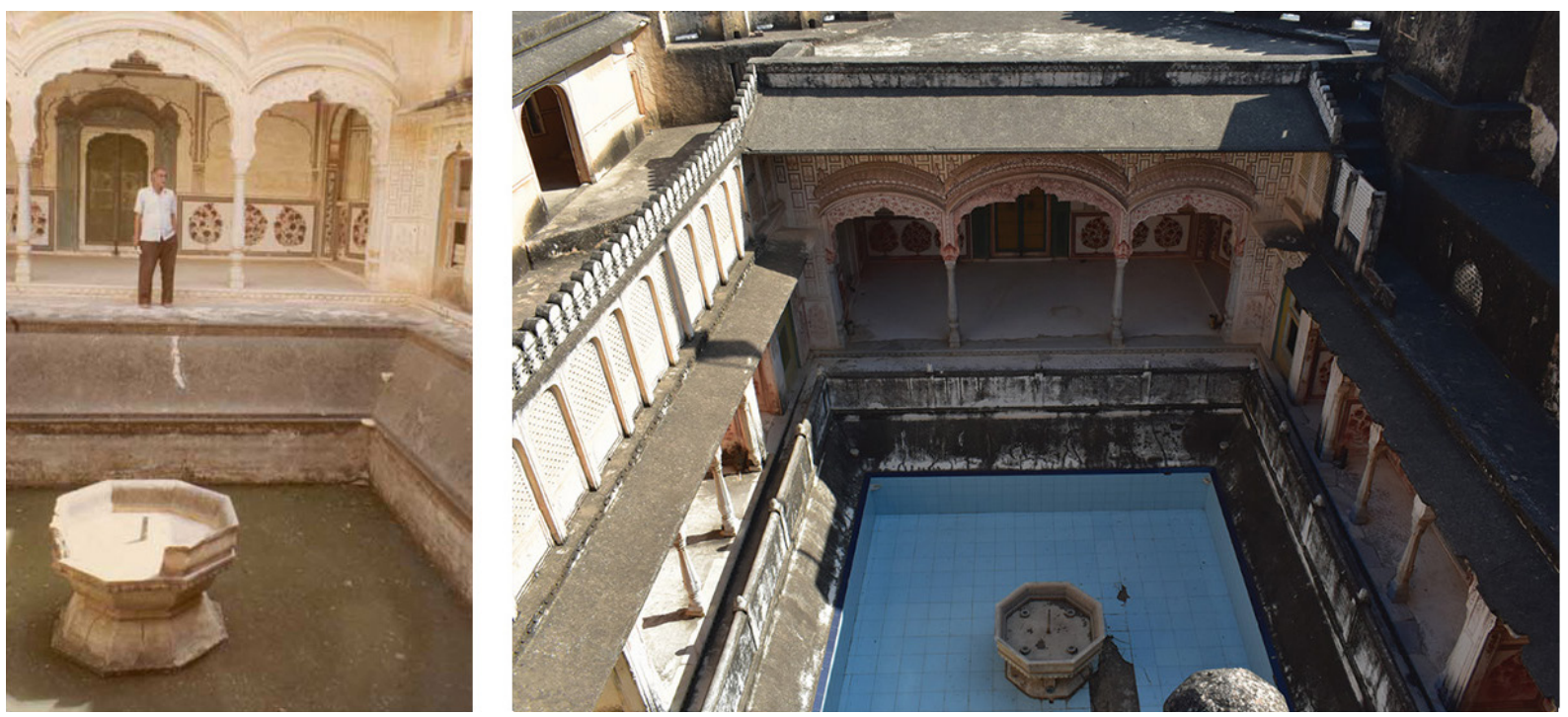


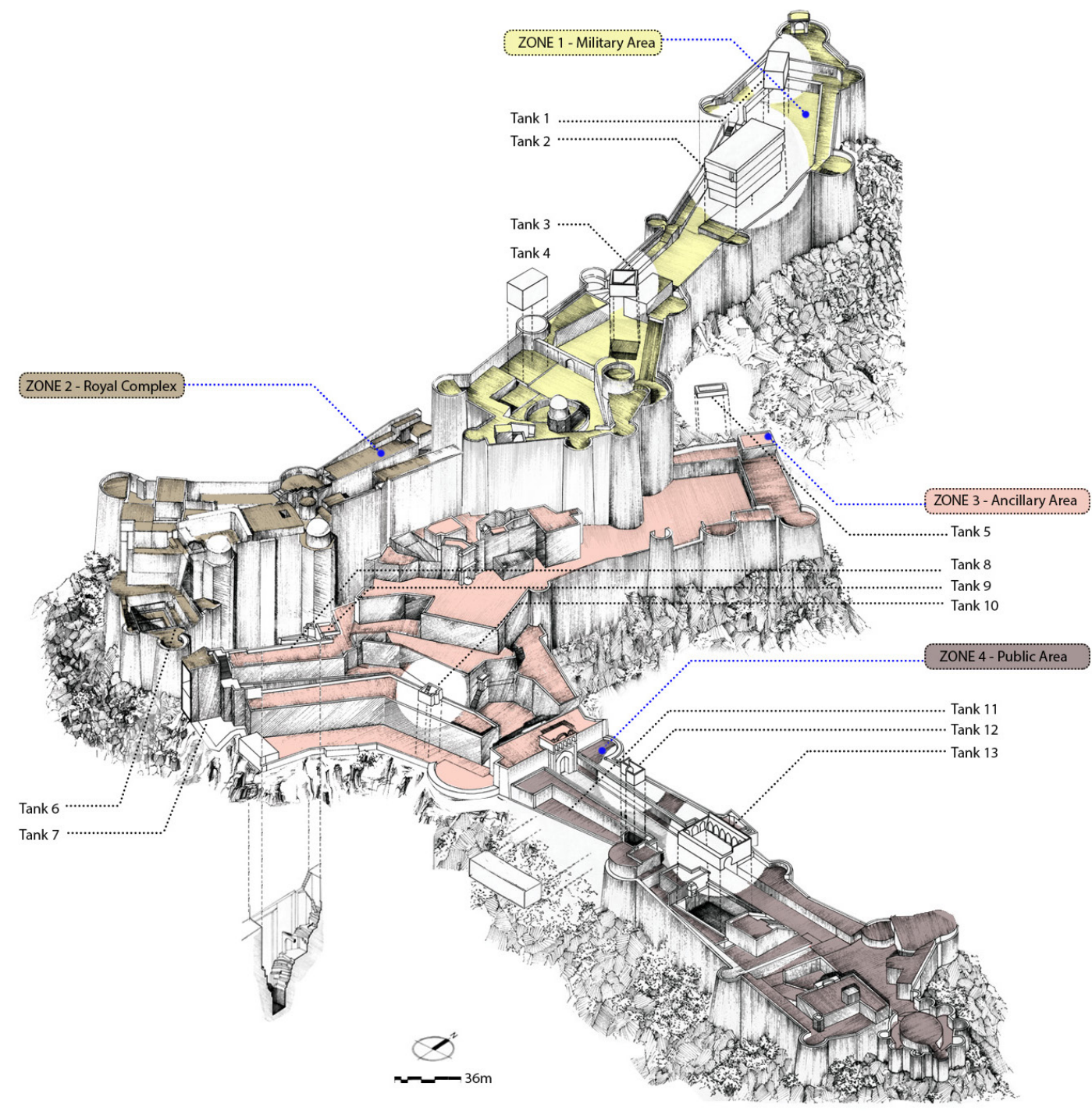

Figure 7: Water tanks in four zones of Kuchaman Fort (made by the authors for the Louis I Kahn trophy, 2017)

they provided an adequate supply of water to the population of the entire settlement. Surface runoff from roads, public spaces or the vacant lands in the settlement is harvested and collected into a talaab at the lower contours of the settlement. These had larger catchments and were mostly impure, so this water was primarily used for washing and irrigation. These structures were not only tangibly, but also intangibly connected through traditional knowledge and cultural reverence, weaving the urban fabric into a whole complex water catchment.

\section{The case of Kuchaman Fort}

Kuchaman is a town in Nagaur, Rajasthan. Kuchaman, a jagir (vassal) in the erstwhile Marwar kingdom, has one of the most impressive fortresses in Rajasthan (Fig. 5). Local folklore even suggests that "the fort is worthy of a queen's birth" (Manohar 2014: 151). Kuchaman Fort was first fortified by the local Gaur Rajputs to control the saltproducing areas that extended from Kuchaman to the salt lake of Sambhar. Zalim Singh, from the Mertia Rajputs of Marwar, was the first Thakur (lord) of Kuchaman. He constructed the current fort in the late eighteenth century (Mishra 2006: 172). Owing to its strategic location, size and socio-economic significance, it expanded gradually, incorporating barracks, palaces, temples and a market. The traditional knowledge of managing water is a prime example of the fort's adeptness to its surroundings. Its location on the leeward edge of the Aravali mountains and the saline groundwater incentivized a system of rainwater harvesting within the fort.

Unlike various heritage properties in Rajasthan, Kuchaman Fort was privately owned. After the independence of India, without the feudal system to back it up, the fort was left unattended. Natural decay did happen, but no drastic conversions were made. In 2000, the fort was converted into a heritage hotel, following the lead of many other heritage structures in Rajasthan. Poor conservation practices were used to convert the fort into a luxury hotel (Fig. 6 ). However, due to its inability to provide a satisfactory experience as such, the hotel at Kuchaman Fort was shut down in $2008^{1}$. 


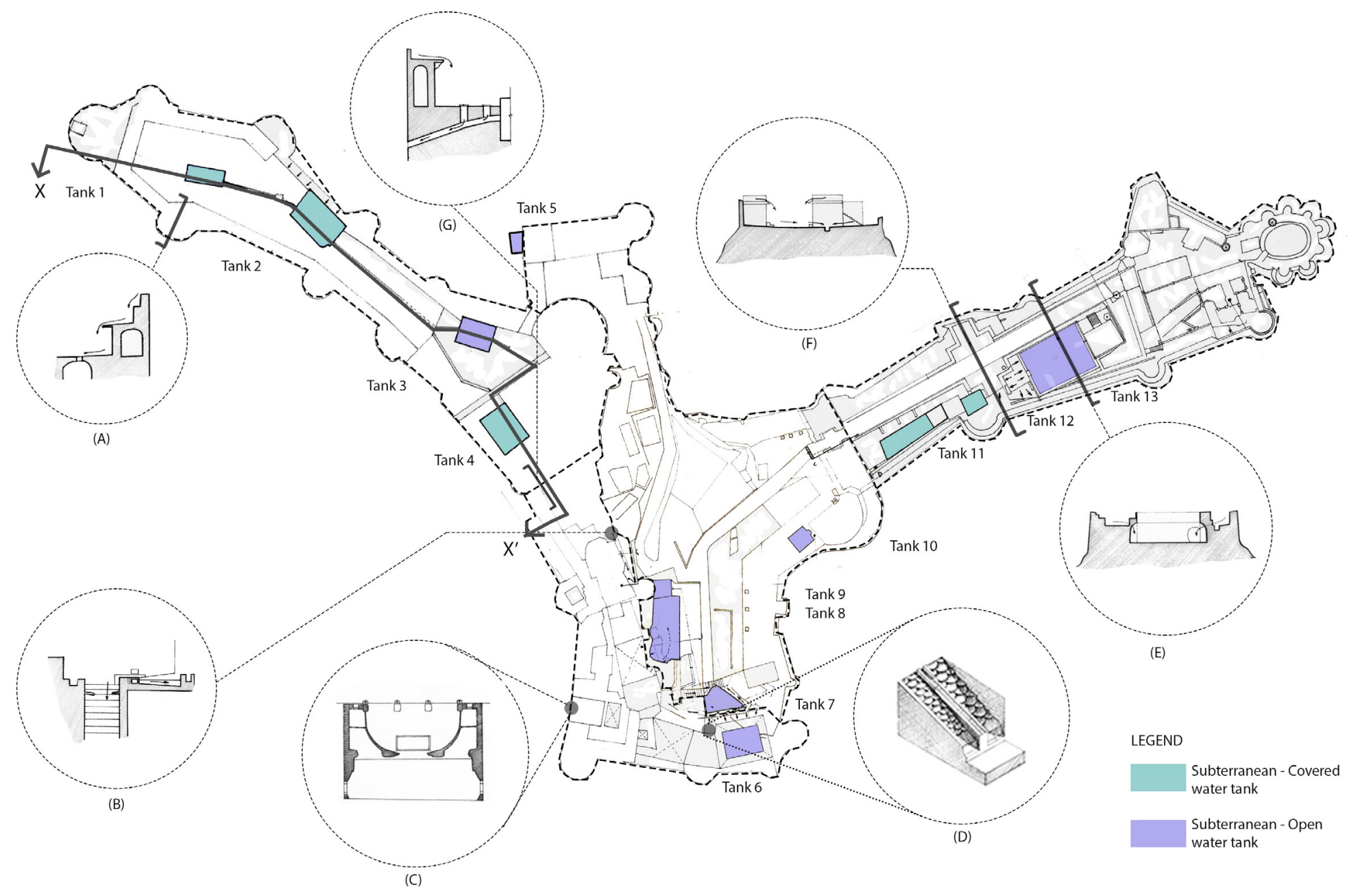

Figure 8: Kuchman fort's catchment area and network of tanks with their unique details: (A) Roof catchments, (B) Flow diverter, (C) Passive cooling mechanism in Hawa Mahal, (D) Water chute with fish scale pattern (E Section through Neeliya Haud (F) Ground catchments and open drains (G) Inspection chambers and underground channels

For ease of understanding, the fort has been divided into four parts based on the purpose of each one, namely the defense zone, the royal zone, the ancillary zone and the public zone (Fig. 7). The defense zone is situated on the highest contour of the hill. It contains the fort's military barracks and provides the best vantage points. This zone comprises the Dhuni Baba's (folk deity) shrine and barracks. Bastions along the periphery are secured with canons and storage for grains and ghee for the soldiers. Below the barracks lies the oldest part of the fort, the Zalim Singh complex. The royal zone of the fort, the Ranvas, comprises temples, residences and leisure spaces, namely, Sheesh Mahal (the royal dressing room), Chameli Chawk (a courtyard with a life-size chessboard), Hawa Mahal (the royal summer residence), and the Sunheri Burj (royal residence with a courtyard pool). The density of the built

Figure 9: Network of tanks and channels in the zone 1

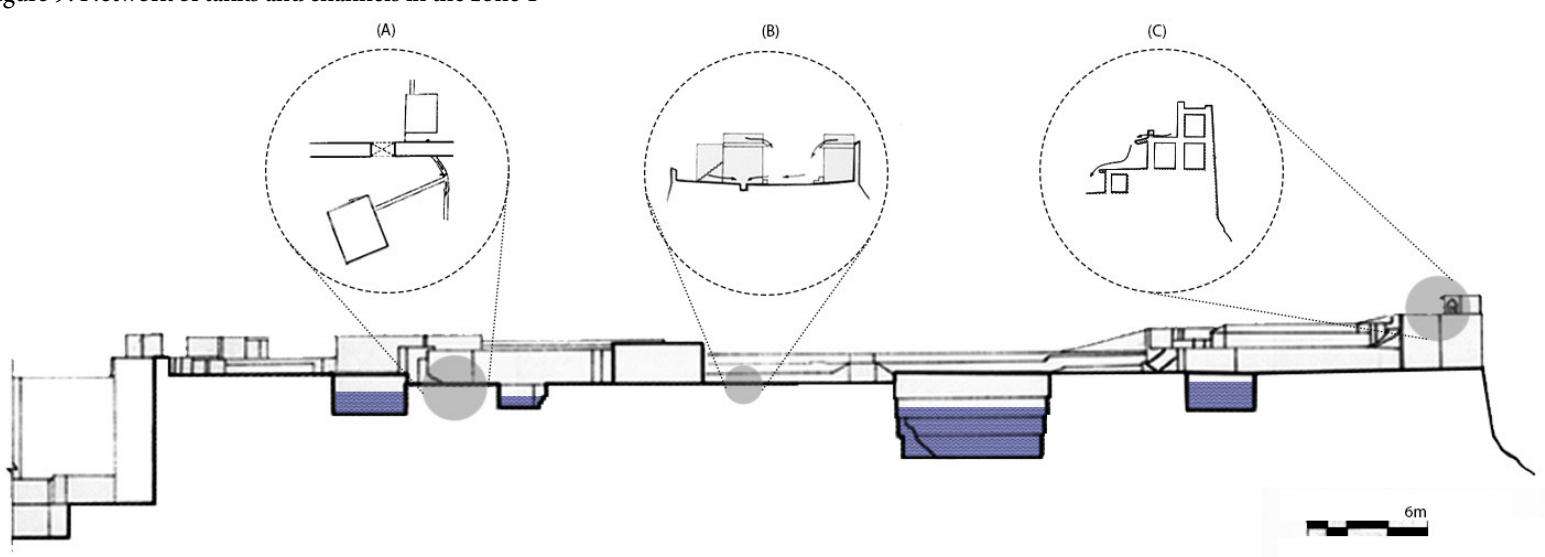




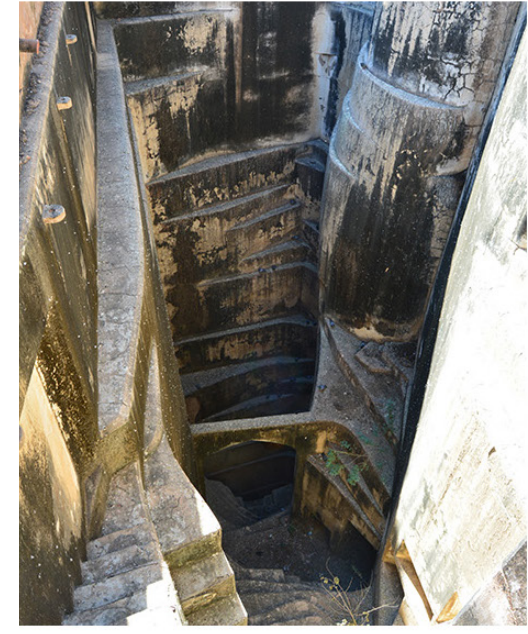

Figure 10: Tank 8, bawdi-1,323.09 $\mathrm{m}^{3}$

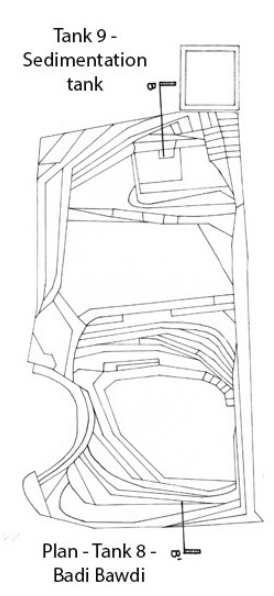

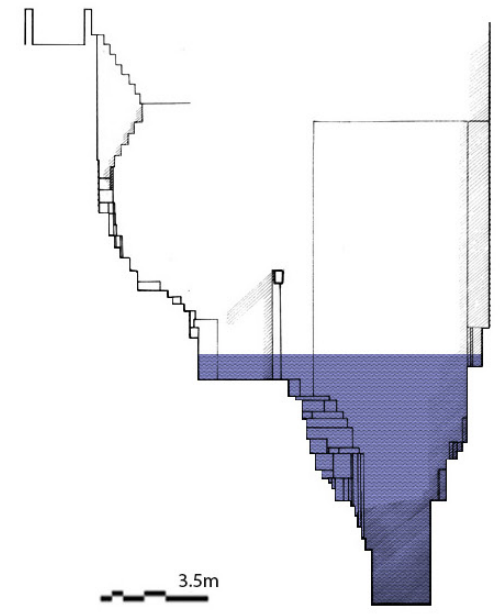

Section through Bawdi form helps keep the zone cool despite its southern location. The buildings are connected by closed pathways which help to maintain the purdah (seclusion) of royal women. The ancillary zone is the semi-private area comprising stables, administrative rooms, the Diwan-e-Khas (the private audience room of the Thakur) and the Chini pol (main gate). This zone is situated at a lower level than the barracks and the Ranvas. It serves as a buffer between the private and public zone of the fort. In the public zone, the Panch Pol serves as the entrance to the fort complex. It also contains the Meena Bazaar, which was laid for the womenfolk of the fort.

The backbone of the fort is its traditional water system. The fort is designed in such a way that all surfaces act as a catchment. This system effectively taps rainwater by channeling it along slopes of the catchments, which is vital to subsistence in the feudal fort.

The water system in the fort comprises three aspects: the rainwater harvesting system (including the storage tanks and their network), water for ornamentation (ornamental laminar flow in the Sunheri Burj of the Ranvas), and water for thermal comfort (evaporative cooling on the balcony of the Hawa Mahal).

\section{$\underline{\text { Rainwater harvesting system }}$}

The catchment slopes at Kuchaman Fort lead to a web of tanks that taps all the rainwater. Most of these tanks are subterranean and provide plenty of water, enough to stand under a long siege if necessary. There were a total of fifteen tanks, of which only thirteen remain, spread over the expanse of the fort, tapping roof and ground catchments (Fig. 8). The placement of the tanks follows the contour of the hill, ensuring that the overflow from one tank goes into another tank. The design of the tanks is befitting the purpose of each one of them: open tanks for greater accessibility and closed tanks to store filtered and potable water achieved by sedimentation. Each zone has at least two tanks, ensuring the availability of water in the vicinity of each built ensemble.

Rainwater harvesting begins at the defensive zone, as it is situated on the highest contour. This zone has four tanks, three underground and one open tank (Fig. 9). During the initial monsoon showers, the inlet to tank 1 and 2 are blocked, and the open tank 3 collects the water. The water collected in tank 3 is not potable as it has cleaned the catchment for the remainder of monsoon. However, it would be used by the military for secondary uses. The subsequent showers are first collected in tank 1, where
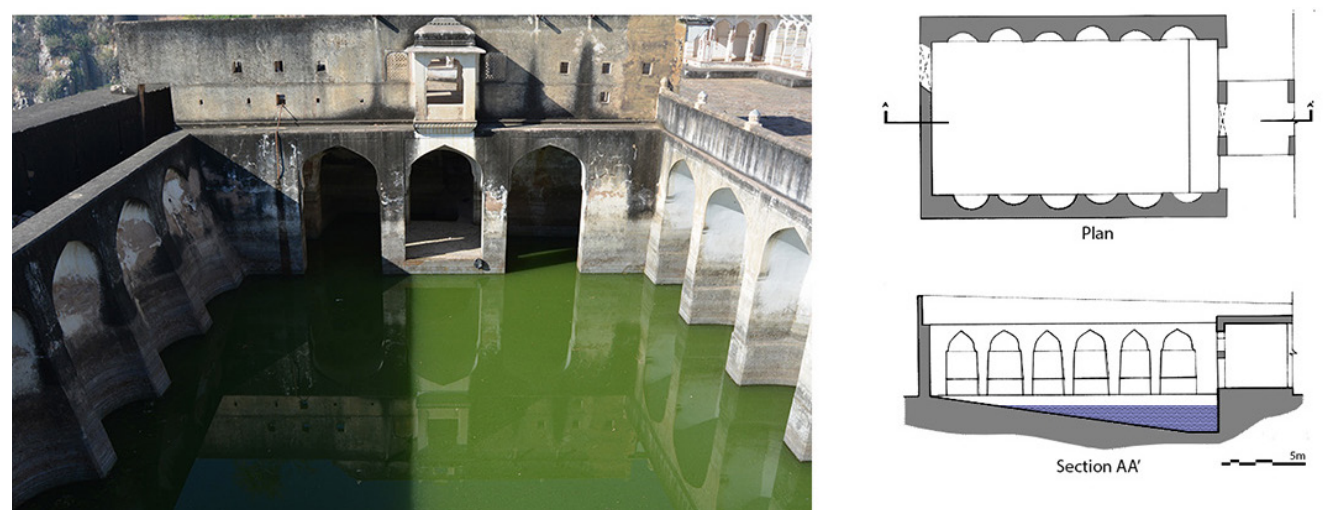

Figure 11: Tank 13, at the Neeliya Haud - $508.83 \mathrm{~m}^{3}$

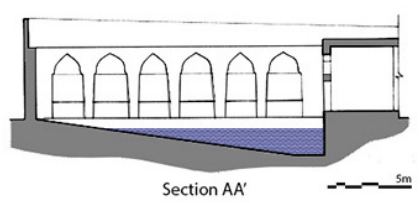



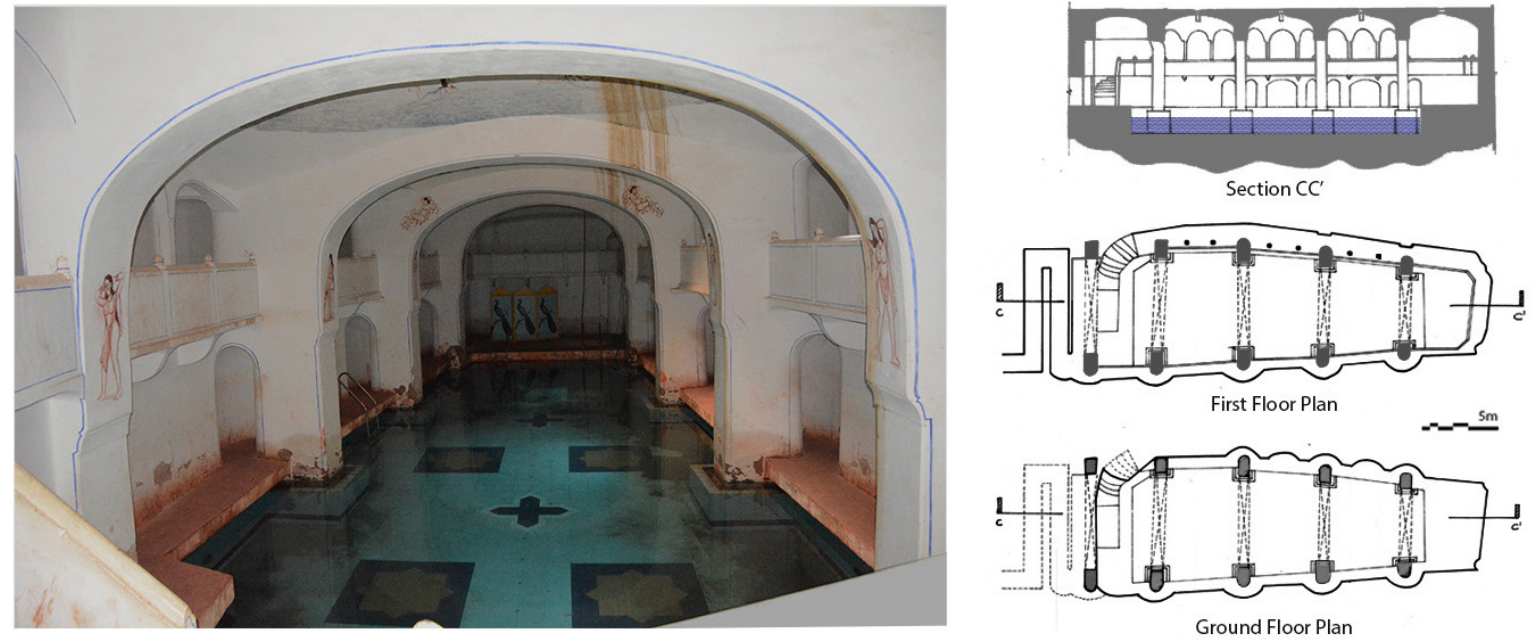

Figure 12: Tank 11, at the Jal Mahal - 1,497.85 $\mathrm{m}^{3}$

the impurities are sedimented, and then tank 2 stores the surplus. Finally, the surplus from tank 2 can be diverted to tank 3 or tank 4, depending on the needs of the military barracks (Fig. 9A). Individual catchments and the surplus tie all the tanks in the fort, ensuring adequate availability.

Due to the scarce water resources in the region, locals embedded frugality in their psyche. Traditionally, water is reused for different purposes, thereby reducing total consumption. For example, tank 7 collects the water from the fountain pool in the Ranvas after it is used for a celebration. It is important to note that most impurities in those times were natural and generally non-toxic and could be easily filtered by physical methods of sedimentation, like in the Badi Bawdi sedimentation tank (Fig. 10). Neeliya Haud, an open tank pavilion, was also used by fort's animals (Fig. 11).

When the fort was converted into a heritage hotel, it lost three of its tanks. A collection tank for roof catchment in the royal zone was converted into storage for the kitchen. Another tank, close to the Panch Pol (the entrance to the fort), which was used by the mint, was filled up. Lastly, the most massive underground tank, at Jal Mahal, was converted into a swimming pool (Fig. 12). These modifications led to the degradation of the network of tanks as a whole.

\section{Water for ornamentation}

In a land where water is scarce, the ornamental use of water is atypical. However, it is striking to find an entire courtyard of the Sunheri Burj converted into a pool (Fig. 13), with the chajja (overhang above the arches) laminated with sheets of water. Such luxury was made possible by the ingenuity of the channeling system. The chadar (laminar water flow) is formed when water from the catchments is channeled through the chajja into the pool (Fig. 13). The chadar instils bespoke aesthetic pleasure along with the required thermal comfort.

During monsoon season, rainwater from the nearby built area is collected in tank 6A, located above Sunheri Burj, and channeled along the periphery of the courtyard terrace. The water from the channel drips onto stucco petals and then forms a chadar. On special occasions, a chadar could also be created by manually filling tank $6 \mathrm{~A}$ to provide respite from the summer heat or to impress a guest. Jali or lattice screen on the terrace blocks the visual connection between servants filling the tanks and the event in the courtyard.

The pool in Sunheri Burj, in Ranvas has a fountain operated by a small tank (tank 6B), located on the terrace of the structure (Fig. 14). It was filled manually and a wooden peg

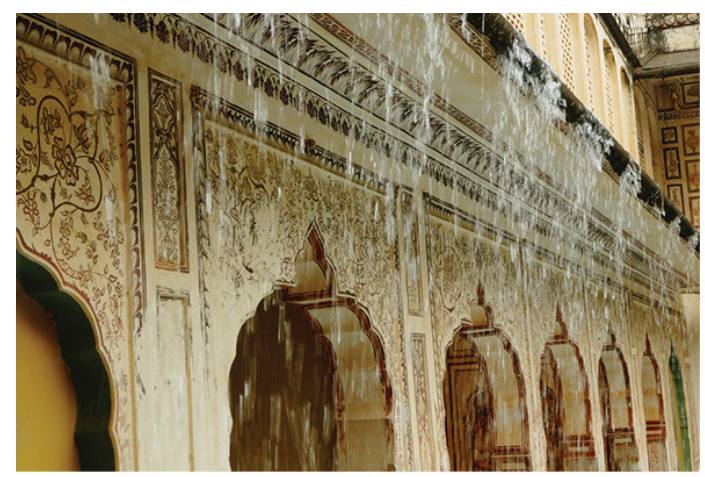

Figure 13: Tank 6, pool in Sunheri Burj, Ranvas - 39.93 m3; (A) Water chadar; (B) Section through the Ranvas pool (made by the authors for the Louis I Kahn trophy, 2017)

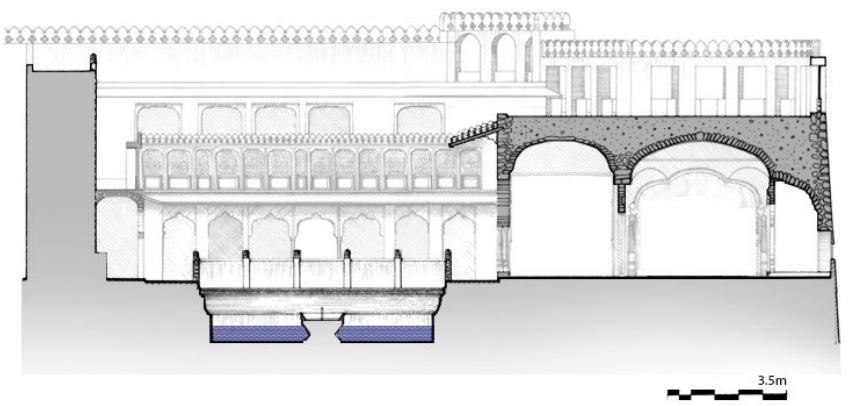




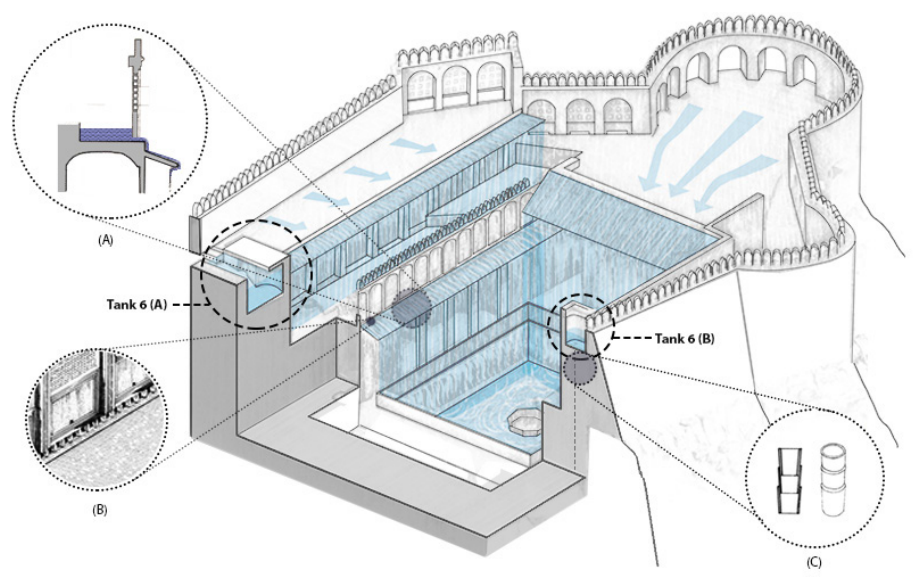

Figure 14 - Formation of chadar in Sunheri Burj, Ranvas; (A) Detail of chajja (B) Design detail above the overhang (C) Sikora cups for channeling (made by the authors for the Louis I Kahn trophy, 2017)

was used as a valve to regulate its flow. The fountain tank is at a higher level than the fountain and employs gravitational force to carry the water. The traditional piping for the fountain was made of sikora, earthen cups punctured and stacked on one another, but is now lost.

\section{Water for thermal comfort}

While the previous manifestations of the traditional knowledge of water systems were mainly related to rainwater harvesting and channeling, water was also used to maximize the thermal comfort of the Hawa Mahal (Palace of Wind). As a summer palace comprising a bedroom and a balcony, it uses the prevailing wind direction to provide thermal comfort in the summer. The room is located in the south-west, with its balcony facing the west.

Hawa Mahal's most critical element is its balcony, which offers an excellent view of the kingdom, apt for a ruler. Its unique design is accentuated by its placement along the prevailing wind direction. When hot afternoon air strikes the closed balcony door, it carries the evaporated water from a small basin on the balcony floor, along the apsidal surface. The shape of the balcony facilitates airflow toward the windows. The windows generate low pressure at the apsidal end and create a surge of cool breeze in the room. The air that strikes the apsidal surface moves along the vortex formed at the apsidal ends. It then joins the wind at the inlet aperture (Fig. 15). Thus, the balcony directs all the moist air inside the room. At night, when the temperature is more habitable, the balcony door is opened to welcome the night breeze.

\section{Design ingenuity of the water system}

The spread of tanks over three zones facilitates the supply of water to spaces with minimum physical activity required. The tanks are also evenly spread over the fort, taking into consideration the requirements of the population and catchment area in each zone. Thirteen tanks connected in a network of sloped pathways and channels were designed to have nearly twice the amount of water that can be harvested from the region's annual rainfall. Water harvested from a year's monsoon could cater to the needs of 250 people $^{1}$ residing within the fort walls for over a year, making the fort resilient to any unforeseen events like a siege or a late monsoon.

The type of tank - open or closed underground tankdefines the quality of its water and thereby the purpose for which it is used. While open tanks with low depths are used as pools for bathing, washing, etc., the larger closed tanks collect and store potable water. The volume of the tank, topography and soil strata in the location define the geometry of each tank. Smaller tanks are mostly cuboidal with more considerable depths and have stepped sides that serve as retaining walls, while domed or vaulted roofs cover the closed tanks with greater surface areas. The ratio of depth to the surface area of the structures varies for open and closed tanks, as open tanks have smaller surface areas to limit evaporation losses. The geometry of larger open tanks, where surface areas decrease with depth, is designed for ease of maintenance - lower surface area at the bottom makes cleaning sediments from the tank floor easier.

Surface treatment of the catchment is done as per the slope gradient to ensure proper runoff-surfaces. Lighter

Figure 15: Water system at the Hawa Mahal's balcony for thermal comfort, (A) Water-cooled air circulation when door is closed, (B) Air circulation when door is kept open, (C) Isometric view of the Hawa Mahal (made by the authors for the Louis I Kahn trophy, 2017)

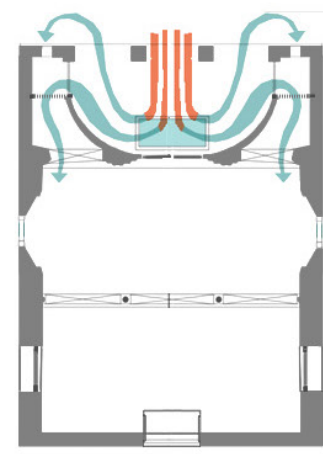

(A)

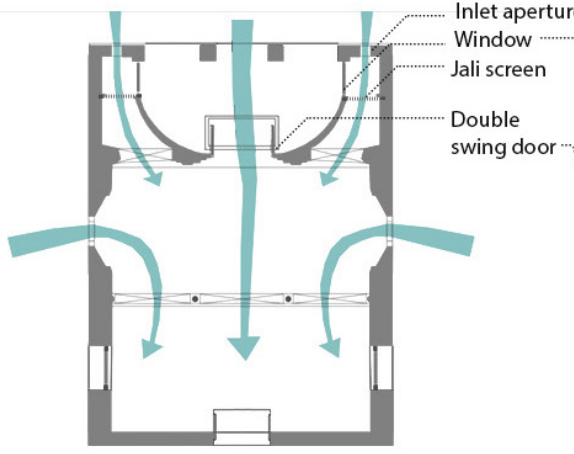

(B)

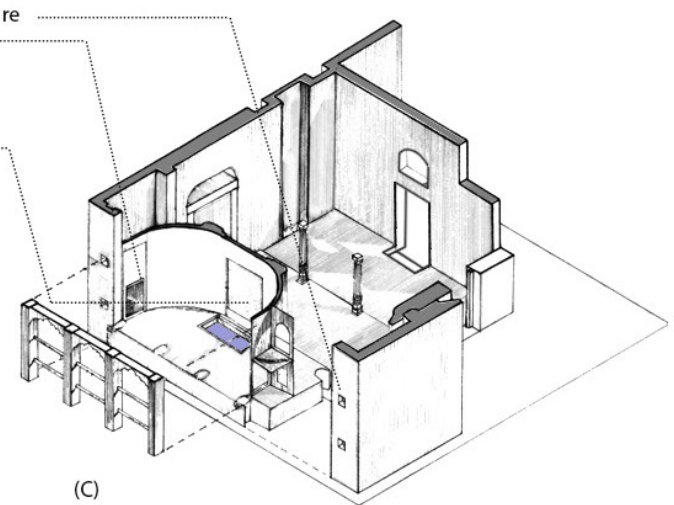




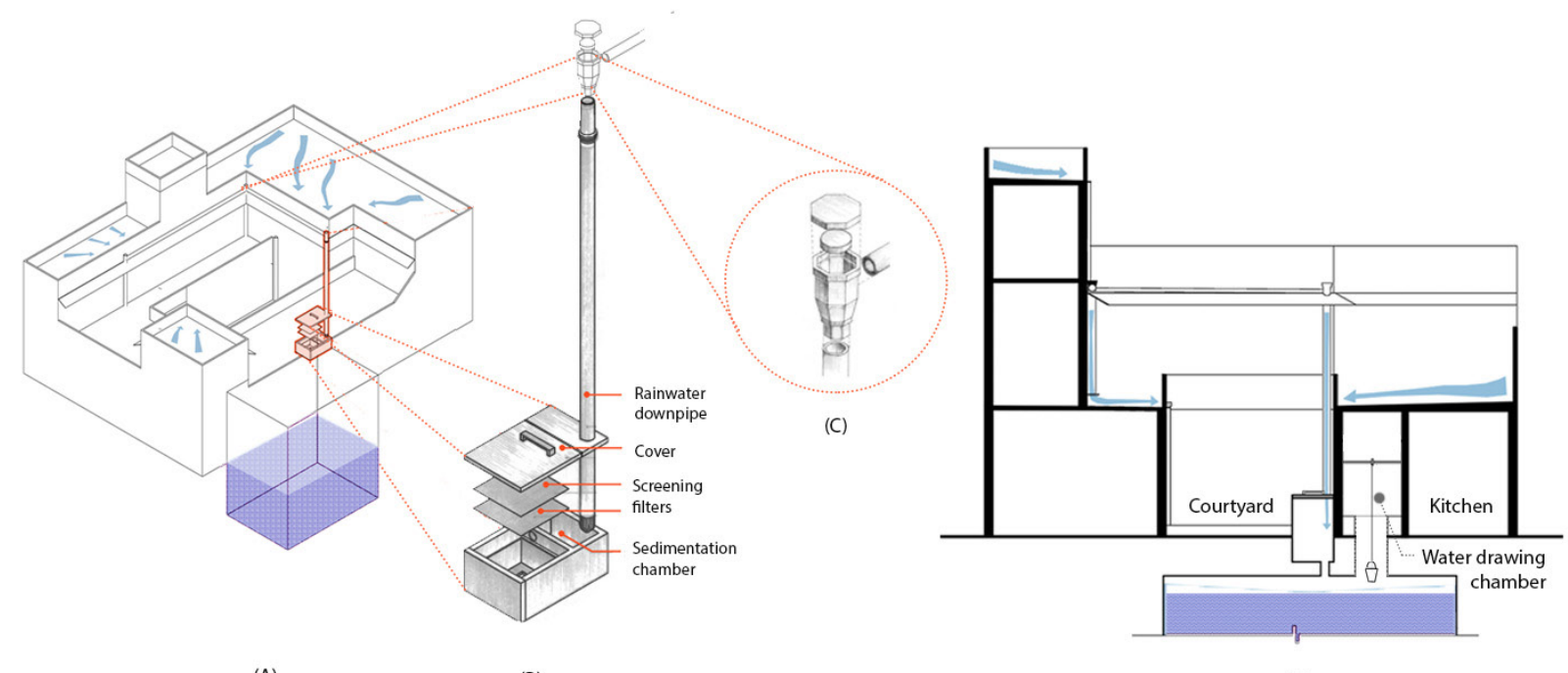

(A)

(B)

(D)

Figure 16: Water system in Rathi Haveli, (A) Isometric view: catchment, channeling and storage, (B) Detail of downpipe and filtration chamber, (C) Diverter valve, (D) Section through the water tank

slopes are plastered with lime, while the steeper slopes are stone-paved. The channels connecting tanks are fitted with chambers that operate as diverter valves to regulate the flow of water into a separate tank as per requirements. The channels take advantage of the natural topography of the hill to create required pressure for the flow of water to fill the tank. Driven by the cultural notion of frugal use of water, the tanks are segregated into units that store freshwater for primary needs and water to be reused for secondary activities separately.

In addition to efficiency in harvesting and storing rainwater, this system also feeds water to the royal complex's ornamentation devices - a fountain in Ranvas, and a chadar, while channeling water from one tank to another. The result is a singular display of the design and aspiration of the Kuchaman Fort.

\section{The case of the Rathi Haveli}

A common people's residence dating back to the period of erstwhile royalty, Rathi Haveli is a 150 -year-old courtyardstyle mansion equipped with a rainwater harvesting system that is based on the same water conservation system described in the fort. This structure is one of the few examples in Kuchaman city which still uses the traditional rainwater harvesting system to date.

The system comprises a defined catchment area - the roof of the building -, connected to a storage facility - a taanka (tank) -, using metal pipes (Fig. 16). The roof of the structure is plastered to create a gradual slope towards drains at three points along the parapet. It is connected to downpipes through gutter outlets. Each gutter outlet is fixed with a diverter valve-like device, used to drain water from the first shower of the season that cleans the catchment area. Once the roof is clean, the valve is closed, and water from subsequent showers is collected into the taanka through the inlet chamber. The closed inlet chamber consists of two sections. The first section is a sedimentation chamber, where impurities settle at the bottom and allow clear water to flow into the second chamber. The water in the second chamber flows through two filters before entering the storage unit - a taanka.

The taanka, a 7 metres deep underground stone masonry tank, spreads through the entirety of the courtyard and expands under a portion of the building near the kitchen. The outlet, as per cultural norms of the family, is enclosed in the well-guarded chamber next to the kitchen. It is fitted with a pulley system to draw water when required. According to the local traditions, only a member of the family can enter this chamber after they have satisfied their standards of cleanliness, to ensure there is no scope for polluting or contaminating the water. This carefully designed system can hold enough water to cater to the potable water requirements of the family for over eighteen months.

A few modern-day adaptations of the architectural elements that support the functioning of this system: the transition of channelling devices from open gutters along parapets to closed pipes, and a closed chamber around the outlet of the tank to ensure the purity of water. This system that is based on the principle of play of slopes has survived the test of time. The simplicity and cost-effectiveness of the design have made it a promising alternative to externally sourced, piped water supply provided by the city authorities. 


\section{Efficiency of the water system in Kuchaman Fort and Rathi Haveli}

Just like the harsh arid climate, the principles and virtue of rainwater harvesting are shared by the royalty and commoners alike. A quantitative analysis of the traditional rainwater harvesting system in both the fort and the Rathi Haveli has been done to highlight its efficiency. The catchment area of the fort $-10,584 \mathrm{~m}^{2}$, together with the annual rainfall of the region $-428 \mathrm{~mm}(0.428$ $\mathrm{m})$, shows that an approximate 4.5 million litres of water can be harvested if the network of tanks were in working condition. As it has been already mentioned, this quantity of water could cater to the fort's population, 250 people, for over a year, taking into consideration the lifestyle that encouraged frugal use and reuse of water. According to the present day requirements of the fort, if converted to a hotel accommodating nearly 180 people ${ }^{1}$, the network of tanks and channels, if revived, could provide for the complete water requirements of the hotel for almost six months.

In the case of Rathi Haveli, as the scale of the catchment area is reduced, the modern-day water requirements of the residents are not wholly catered to by the system. However, the rainwater harvested through the network serves the potable water requirement of the family for over eighteen months. Groundwater pumped using a bore well, which cannot be used for drinking and cooking due to its high salinity, is used to meet the secondary needs of the family.

The numerical evidence from the two cases detailed above emphasizes the efficiency of the system. It suggests that the revival of this traditional water conservation system could prove to be a sustainable alternative to the existing system of externally sourced water supply. The traditional perspective can be re-asserted through modern thinking to envision sustainable alternatives (Narain and Agarwal 1999).The identified principles of the traditional water system could be incorporated into the mainstream practice by translating them into an architectural vocabulary which can be up-scaled and improvised by many.

\section{Principles of the traditional knowledge system to upgrade contemporary practice}

The major principles that define the functioning of the traditional knowledge system identified in the two studied cases are now listed. Context-specific design of built forms that support the system, based on these principles could be employed in contemporary practice and make other settlements more resilient.

1. "Catch every drop of water where it falls" (Mishra 2009): increasing harvesting capacities through carefully engineered surface treatment, and storage units spaced uniformly in proximity to built forms. It is also relevant to minimize physical activity for supply and transfer of the resource.
2. Decentralization: diverse, contextually designed structures which allow decentralizing water harvesting and storage. They can be structures of various typologies: individual, communal or public. It makes the system more resilient.

3. Inclusivity: design of water storage structures which are inclusive and cater to needs of all living beings across species, social and cultural groups.

4. Social and cultural layering to develop an integrated mechanism: the community's cultural and religious association to water storage structures, observed in the intricacy of ornamentation, and deep-rooted reverence for the resource that is passed onto generations through folklore, traditions and way of living, has facilitated sustenance of the knowledge system.

\section{Conclusion}

A shift in attitudes and blind exploitation of resources has put us on the path of unsustainable consumption. In our search for alternative solutions, it is rational to examine the traditional wisdom that had readily dealt with the same issues which are the systemic roots of the current crisis. This study, based on the case of Kuchaman, emphasises the need to employ traditional systems of harvesting and managing water as a viable alternative to the non-locally sourced centralised piped water supply. Documentation of the water system in both structures provides evidence, in terms of volumes, of its viability. The evolution of the system over the years from the royal complex to the common people's house has shown the changes in built forms and devices that support the working of the system. Learning from these cases, a set of principles for designing a modern-day adaptation of the traditional system has been presented.

A network of tanks and channels customised to fit the topography and planning of a settlement aided by carefully engineered surfaces, slopes and storage units, as seen in the example of Kuchaman fort, could be scaled up to be operated in other settlements of the studied region. Reducing the dependence on externally sourced resources and decentralisation of collection and supply structures would ensure a continued supply of water even if one of the structures is out of order, thereby making the settlement more resilient. Festivals and traditions help in reinforcing the knowledge system to perpetuate by encouraging propagation of cultural and religious association of water through folklore. The presented study is a start to the exploration of manifestations of indigenous knowledge on water systems.

${ }^{1}$ Manvendra Singh Shekhawat, "Heritage as a resource for placemaking and its commercial optimisation", interview by VIkramaditya Singh Rathore, April 18, 2020. 


\section{Bibliography | Bibliografía | Bibliografia}

Jacob, Nitya. Jalyatra: Exploring India's Traditional Water Management Systems. Online publisher: Createspace Independent.

Manohar, Raghavendra Singh. 2014. Rajasthan ke pramukh durg. Jaipur: Rajasthan Hindi Granth Akademi.

Mishra, Anupam. 1993. Aaj Bhi Khare Hein Talaab. Delhi: Gandhi Shanti Pratishthan.

Mishra, Anupam. 1995. Rajasthan ki Rajat Boondein. Delhi: Gandhi Shanti Pratishthan.

Mishra, Anupam. 2009, November. Anupam Mishra: The ancient ingenuity of water harvesting. TED: https://www.ted.com/talks/anupam mishra_the_ancient_ingenuity_of_water_harvesting?language $=$ en (consulted on 29/09/2020)

Mishra, Ratanlal. 2006. Small forts of Rajasthan. In Mishra, Ratanlal. Saga of Forts and Fortifications of Rajasthan: A peep into their resplendent glory. New Delhi: B.R. Publishing Corporation.

Narain, Sunita, \& Agarwal, Anil. 1999. Making Water Management Everybody's Business: Water Harvesting and Rural Development in India. Gatekeeper series, SA87: 3-15.

\section{Biographies | Biografías | Biografias}

\section{Vikramaditya Singh Rathore}

$\mathrm{He}$ is an architect, graduated from the School of Planning and Architecture, Bhopal. He has a passion for traditional built practices and its modern implications. He has been a part of teams which have won several competitions by the Indian National Trust for Art and Cultural Heritage (INTACH), Traditional Architecture Group of the Royal Institute of British Architects (RIBA) and others.

\section{Jahnavi Kantamneni}

She is an architect, graduated from School of Planning and Architecture, Bhopal, in 2020. With a keen interest in learning from traditional knowledge systems, she intends to pursue research on bottom-up approach of design for disaster resilience, and impact of climate change on buildings.

\section{Ajinkya Jamadar}

$\mathrm{He}$ is an architect, graduated from the School of Planning and Architecture, Bhopal. He has interests in the domains of design cultures, traditional knowledge systems, socio-ecological dynamics and systemic thinking. He has been a part of teams which have won several competitions by the Indian National Trust for Art and Cultural Heritage (INTACH), Traditional Architecture Group of the Royal Institute of British Architects (RIBA) and others.

\section{Subham Anupam}

$\mathrm{He}$ is an architect, graduated from the School of Planning and Architecture, Bhopal, and currently working at Flying Elephant Studio, Bangalore. He has interests in the domains of design thinking, contemporary vernacular, urban design, and systemic thinking. He has been a part of teams which have won several competitions by the Indian National Trust for Art and Cultural Heritage (INTACH), Traditional Architecture Group of the Royal Institute of British Architects (RIBA) and others.

\section{Devanshi Kachchap}

She is an architect, graduated from the School of Planning and Architecture, Bhopal, and currently working at Chadda and Associates, Ranchi. She has a keen interest in the field of architectural design, urbanism, and the traditional knowledge system. She has been a part of teams which have won several competitions by the Indian National Trust for Art and Cultural Heritage (INTACH), Traditional Architecture Group of the Royal Institute of British Architects (RIBA) and others. 